\title{
Number of muscle fibres in adult Atlantic cod varies with temperature during embryonic development and pantophysin (PanI) genotype
}

\author{
Ian A. Johnston ${ }^{1, *}$, Øivind Andersen ${ }^{2,3}$ \\ ${ }^{1}$ School of Biology, University of St. Andrews, St. Andrews, KY16 8LB, UK \\ ${ }^{2}$ Nofima, PO Box 5010, 1432 Aas, Norway \\ ${ }^{3}$ Aquaculture Protein Centre CoE, PO Box 5003, 1432 Aas, Norway
}

\begin{abstract}
We investigated the effects of development temperature and pantophysin (PanI) genotype on muscle fibre recruitment in Atlantic cod Gadus morhua L. reared under controlled laboratory conditions. Fertilized eggs of farmed cod originating from the Norwegian coastal (NC) and northeast Arctic stock (NEA) were incubated at 4,6 or $8^{\circ} \mathrm{C}$ until hatching. At hatching, the number of fast myotomal muscle fibres (determined at 0.7 standard length) was generally greater at higher rearing temperature $\left(10.4 \%\right.$ greater at 8 than at $4^{\circ} \mathrm{C}$ in NEA cod) and was greater for NC than for NEA populations $\left(32.7 \%\right.$ greater at $\left.4^{\circ} \mathrm{C}\right)$. After first feeding, the temperature groups were reared under identical feeding and environmental conditions until the final number of fast myotomal muscle fibres was reached by adult fish. Development temperature and PanI genotype affected the final number of myotomal muscle fibres (FFN) in adult cod. In the NEA population, $\mathrm{FFN}$ was $11 \%$ higher at $4^{\circ} \mathrm{C}$ $(92000 \pm 4000 \mathrm{SE}, \mathrm{n}=13)$ than at $8^{\circ} \mathrm{C}(83000 \pm 3000 \mathrm{SE}, \mathrm{n}=20)$, reversing the trend seen at hatching. Analysis of the NEA population revealed that FFN was $16 \%$ higher in $\operatorname{PanI}^{\mathrm{BB}}(\mathrm{n}=19)$ than in $\operatorname{PanI}^{\mathrm{AB}}$ $(\mathrm{n}=27)$ genotypes (Tukey's test; difference of means \pm SE: $12900 \pm 3400 ; \mathrm{p}=0.001)$. Results indicate association between the PanI locus and the gene(s) regulating the final muscle fibre number, and also demonstrate persistent effects of embryonic environment on adult muscle phenotype.
\end{abstract}

KEY WORDS: Muscle growth $\cdot$ Hyperplasia $\cdot$ Developmental plasticity $\cdot$ Temperature $\cdot$ Gadus morhua

Resale or republication not permitted without written consent of the publisher

\section{INTRODUCTION}

The Atlantic cod Gadus morhua L. is distributed on the continental shelves and banks on both sides of the North Atlantic Ocean. Identification of stocks remains controversial, although there is evidence of considerable population sub-structuring over small geographic scales (reviewed in Imsland \& Jónsdóttir 2003). In Norwegian waters, 2 major populations have been identified - the Norwegian coastal (NC) and the northeast Arctic (NEA) stocks. NEA cod migrate from feeding areas in the Barents Sea and near Svalbard to spawn along the Norwegian coast, most importantly near the Lofoten Islands (Brander 1994). Although NC and NEA cod may simultaneously be present at the same local spawning ground, they probably do not mix randomly (Nordeide 1998), and may have pre-mating mecha- nisms that reduce or prevent interbreeding between populations (Nordeide \& Folstad 2000). The polymorphic pantophysin (PanI) locus, which encodes an integral membrane protein of unknown function, has been particularly useful in discriminating among populations in the northeast Atlantic (Pogson et al. 1995, Pogson 2001, Case et al. 2005). The frequencies of the identified $\operatorname{PanI}^{\mathrm{A}}$ and $\operatorname{PanI}^{\mathrm{B}}$ alleles show extensive differentiation between cod populations (Karlsson \& Mork 2003, Pogson \& Fevolden 2003), with salinity, depth and particularly temperature identified as potential environmental factors driving selection (Case et al. 2005). The frequency of the $\operatorname{PanI}^{\mathrm{B}}$ allele was found to be much higher in northeast Arctic (0.90) than in coastal (0.19) cod populations (Fevolden \& Pogson 1997). The somatic growth of the $P a n I^{\mathrm{BB}}$ genotype was found to be lower than that of the PanI ${ }^{\mathrm{AA}}$ genotype in 
several wild populations without elucidating the specific effects of genetic and environmental factors (Fevolden \& Pogson 1997, Jónsdóttir et al. 2002). By studying the offspring of 3 Atlantic cod families in a controlled laboratory experiment, Case et al. (2006) recently showed that larvae carrying the $\operatorname{Pan} \mathrm{I}^{\mathrm{AB}}$ genotype exhibited higher weight and length than $\operatorname{PanI}^{\mathrm{BB}}$ larvae.

The number of muscle fibres is one of a number of morphological traits (see Greer-Walker et al. 1972) which, along with meristic characters such as vertebrae number (Løken et al. 1994), show differentiation between populations, and are known to have a genetic and developmental origin (Hempel \& Blaxter 1961, Johnston 2006). The temperature prior to hatching has been shown to affect the timing and intensity of muscle hyperplasia as well as fibre size in larval stages in a number of marine fishes including the Atlantic herring Clupea harengus (Johnston et al. 1998), plaice Pleuronectes platessa (Brooks \& Johnston 1993), sea bass Dicentrarchus labrax (López-Albors et al. 2003), Atlantic cod (Hall \& Johnston 2003) and haddock Melanogrammus aeglefinus (Martell \& Kieffer 2007). The effects of embryonic temperature on fibre number were no longer apparent following metamorphosis in sea bass (López-Albors et al. 2003), but persisted in Atlantic herring (Johnston et al. 1998). In Atlantic salmon Salmo salar, early thermal experience produced up to a $20 \%$ difference in the final fibre number (FFN) between temperature treatments in the adult fish (Johnston et al. 2003, Macqueen et al. 2008). Phenotypic variation in final fibre number is of importance to the physiology of the whole organism since it is likely to affect growth rate and routine energy requirements (Johnston 2006).

The Atlantic cod is one of the most valuable commercial species of the northern Atlantic region, and wild stocks are currently in decline (Walters \& Maguire 1996). Recently, considerable effort has been expended in developing an aquaculture technology for the Atlantic cod. In this context, it is important to investigate growth traits such as FFN under controlled conditions, particularly as fibre density is correlated with flesh firmness in some species (Johnston et al. 2000a). The present study aims to investigate the influence of both development temperature and PanI genotype on muscle fibre recruitment in coastal and northeast Arctic cod populations.

\section{MATERIALS AND METHODS}

Fish. The fish studied came from the F2 generation of farmed Atlantic cod originating from wild broodstock caught in 2 geographically distant localities (off Andenes, Nordland county: 14 o +23 ơ; and Møre \& Roms- dal county and Nord-Trøndelag county: 20 o $+29 o^{7}$ ) in March and February 2002, respectively (Gjerde et al. 2004). Fertilized eggs were obtained on 18 March 2005 from mass spawnings of fish held in $14 \mathrm{~m}^{3}$ tanks at Akvaforsk, Averøy, on the west coast of Norway. The first cell divisions were microscopically examined, and high-quality eggs were immediately transferred to Akvaforsk, Sunndalsøra, for incubation in seawater (33 ppm) in 17 l cylindrical fibreglass units placed in the dark. Both NEA and NC eggs were incubated in duplicate tanks at either 4,6 , or $8^{\circ} \mathrm{C}$ until hatching. After hatching, the larval groups were transferred to duplicate 331 black cylindrical tanks at $8^{\circ} \mathrm{C}$ and fed a commercial starter feed enriched with rotifers and Artemia spp. as described by Gjerde et al. (2004). First feeding took place at 17,22 and $30 \mathrm{~d}$ post-fertilisation for the 8,6 and $4{ }^{\circ} \mathrm{C}$ treatments, respectively. Due to high mortality during this critical period, the number of coastal cod from the 4 and $8^{\circ} \mathrm{C}$ incubation groups was greatly diminished, and had to be excluded from the study. Metamorphosed larvae were transferred to 801 tanks and weaned onto dry feed as described by Gjerde et al. (2004). The criterion used for the identification of metamorphosis was the appearance of fin rays in the dorsal and ventral unpaired fins (Galloway et al. 1999). The fish were passiver integrated transponder (PIT)-tagged at a mean weight of $20 \mathrm{~g}$ and kept separate in duplicate groups until transfer to a $120 \mathrm{~m}^{3}$ sea cage at Akvaforsk, Averøy.

Fish were sampled $\left(\mathrm{n}=10 \mathrm{tank}^{-1}\right.$ population $\left.{ }^{-1}\right)$ for muscle analysis during the first week of the following months: June 2005, March 2006, September 2006 and February 2007. Body mass and standard lengths were recorded for each sample. To identify PanI genotypes in the last 2 samples, a fin clip was taken for DNA analyses and stored in absolute ethanol at $4^{\circ} \mathrm{C}$.

Analysis of muscle growth. Larvae were over-anaesthetized in MS-222, fixed overnight in $4 \%(\mathrm{~m} / \mathrm{v})$ paraformaldehyde in phosphate-buffered saline (PBS) containing $10 \%(\mathrm{~m} / \mathrm{v})$ sucrose, and stored in PBS containing $0.1 \%(\mathrm{~m} / \mathrm{v})$ sodium azide. A section of trunk muscle corresponding to 0.4 to 0.8 standard length (SL, measured from the tip of the snout to the posterior end of the last vertebrae) (see Fig. 1a) was frozen in isopentane cooled to its freezing point in liquid nitrogen $\left(-159^{\circ} \mathrm{C}\right)$. Juvenile and adult cod were euthanized by hitting the head and pithing the brain. A $0.5 \mathrm{~mm}$ thick transverse section through the trunk muscle at $0.7 \mathrm{SL}$ was prepared and photographed. Sufficient blocks were prepared in order to sample all of the muscle on one side of the trunk ( 1 block in the smallest fish and up to 8 blocks in the largest fish). Frozen sections from larval and juvenile/adult stages were cut at $8 \mu \mathrm{m}$ on a cryostat (Leica Microsystems, CM1850). All sections were mounted on poly-L-lysine-coated slides and air dried for storage at $-80^{\circ} \mathrm{C}$. 
The distribution of fast muscles was investigated by staining sections with Harris's haematoxylin, succinic dehydrogenase and glycogen, and that of slow muscle myosin with the S58 antibody as described in Johnston et al. (2004). This enabled us to identify fields of pure fast muscle fibres for quantification of fibre size in the sections stained with Harris's haematoxylin. The total cross-sectional area of the fast muscle in the myotome was determined from digital photographs of sections (larvae) and the whole trunk cross-section (juvenile/ adult stages). The outlines of all the fast muscle fibres per field $\left(0.15 \mathrm{~mm}^{2}\right)$ within a randomly selected square grid were digitized using SigmaScan Pro image analysis software (SYSTAT). For larvae, all the fast muscle fibres in one half of the trunk were quantified. For juvenile and adult fish, a total of 1000 fibres evenly distributed among the total number of blocks were measured per fish. Muscle fibre number and diameter were estimated as described in Johnston et al. (1999).

Determination of the final fibre number in adult cod. Adult fish that had no fast myotomal muscle fibres with diameters of $10 \mu \mathrm{m}$ or less were considered to have reached the FFN. Approximately 2/3 of the September 2006 sample and all of the fish from the February 2007 sample fulfilled this criterion. Data on muscle fibre diameter are not reported for adults because of the confounding effects of mixed ages and sizes of fish.

Determination of pantophysin (PanI) genotypes. PanI genotyping was done using a PCR-based assay to score polymorphism at the DraI site in the third intron of the gene as described by Fevolden \& Pogson (1997). Total DNA was extracted from $25 \mathrm{mg}$ of dorsal fin clip using a DNeasy ${ }^{\circledR}$ kit from Qiagen. The following forward (5'-TTGGTCCTCTATCTGGGCTTCG-3') and reverse (5'-CGTAGCAGAAGAGTACACAT-3') primers were used for amplifications. PCR products were digested with DraI and visualised on $2 \%(\mathrm{~m} / \mathrm{v})$ agarose gels stained with ethidium bromide.

Statistics. The body length and mass of larvae were analysed in Minitab using a General Linear Model 2way ANOVA, with population and development temperature as fixed factors and tank as a random effect. Data on larval muscle fibre number and diameter were analysed in R using the library nlme (Pinheiro \& Bates 2000), with a model incorporating population and developmental temperature, and using tank as a random blocking factor. Since the distributional properties of the data on fibre diameter did not conform with the ANOVA assumption of variance homogeneity despite transformation or incorporation of a standard linking function, subsequent analysis was performed on the ranks. The data on FFN in adult cod was analysed using a model incorporating population, development temperature and PanI genotype. FFN conformed with the assumptions of ANOVA without transformation.
The data for the NEA population was also modelled separately to avoid the confounding effects of population and PanI genotype. The $\mathrm{p}<0.05$ level was used to establish statistical significance.

\section{RESULTS AND DISCUSSION}

\section{Larvae}

The distribution of slow and fast muscle fibres and the diameters of fast muscle fibres are shown in Fig. 1. Muscle fibre production (hyperplasia) in the fast myotomal compartment of teleosts occurs in 3 distinct, but often overlapping phases: embryonic myogenesis, stratified hyperplasia (SH) and mosaic hyperplasia (MH) (Rowlerson \& Veggetti 2001, Johnston 2006). There was no evidence that $\mathrm{SH}$ had started in cod larvae at the hatching stage based on the distribution of fast muscle fibre diameters (Fig. 1b), in agreement with a previous study (Galloway et al. 1998). This indicates that all the fast muscle fibres present in the myo-

a

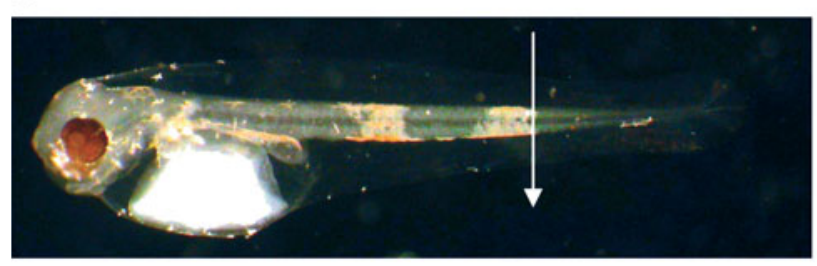

b

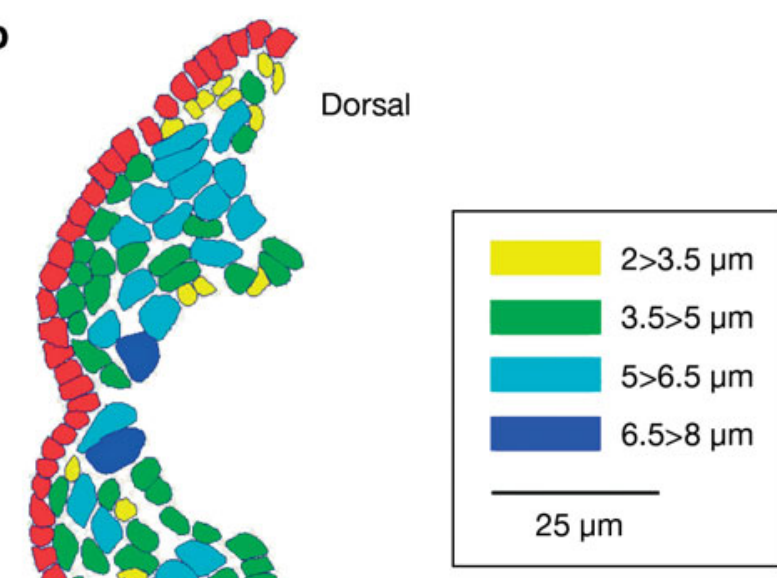

Ventral

Fig. 1. Gadus morhua. (a) Norwegian coastal yolk-sac larva (incubated at $6^{\circ} \mathrm{C}$ ) at hatching showing the position of the section in (b) (arrow). (b) Camera lucida drawing of the muscle fibres. The superficial layer of slow muscle fibres is shown in red. Fast muscle fibres are colour-coded by diameter 
tomes at hatching were derived from embryonic myogenesis.

Preliminary statistical analysis showed no differences between replicate tanks $(p=0.24)$, hence the effect of tank was ignored in subsequent analyses. Egg incubation temperature influenced larval fork length (FL) (Fig. 2a) and the total cross-sectional area (TCA) of fast myotomal muscle fibres (not shown). For example, in the NEA population FL was $20 \%$ greater at an incubation temperature of $4^{\circ} \mathrm{C}$ than at $8^{\circ} \mathrm{C}(\mathrm{p}<0.001)$, whereas TCA was $15 \%$ less at $4^{\circ} \mathrm{C}$ than at $8^{\circ} \mathrm{C}(\mathrm{p}<$ 0.001 ) (not shown). In the NEA population, FL was $9.5 \%$ higher in larvae from eggs incubated at $4^{\circ} \mathrm{C}$ than those at $8^{\circ} \mathrm{C}(\mathrm{p}<0.05)$ (Fig. 2a), whereas the TCAs at
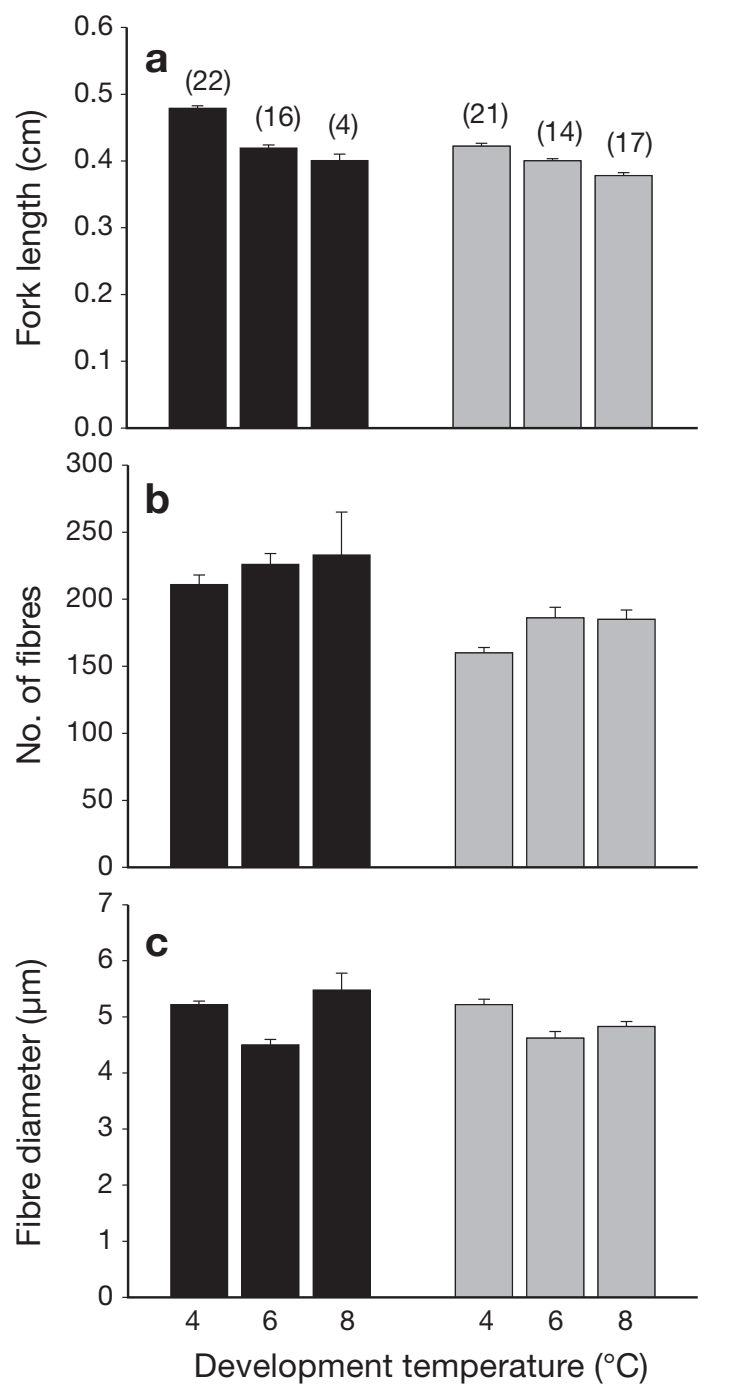

Fig. 2. Gadus morhua. Relationship between embryonic development temperatures and (a) larval fork length, (b) number of fast muscle fibres per trunk cross-section and (c) average diameter of fast muscle fibres. Black bars: northeast Arctic cod; grey bars: Norwegian coastal cod. All results are mean \pm SE. Number of fish sampled is shown in brackets in panel (a) both temperatures were similar (not shown). The number of fibres in larvae was analysed using ranks due to the distributional properties of the data, and both development temperature $\left(F_{2,88}=7.46 ; \mathrm{p}<0.0001\right)$ and particularly population $\left(F_{1,88}=41.0 ; \mathrm{p}<0.0001\right)$ were significant factors in the model, although their interaction was not significant. For both populations, the number of fast muscle fibres was greater at higher development temperature, i.e. 10.4 and $15.6 \%$ greater at 8 than at $4^{\circ} \mathrm{C}$ in NEA and NC populations, respectively (Fig. 2b). There was also a significant interaction between development temperature and population for the average fibre diameter in larvae $\left(\mathrm{F}_{2,88}=4.60\right.$; $\mathrm{p}<0.001$ ) (Fig. 2c). In a previous study involving farmed cod of western Scottish origin, no significant differences in number of fibres at hatching were found for incubation temperatures of 4 and $7^{\circ} \mathrm{C}$, whereas the $10^{\circ} \mathrm{C}$ treatment resulted in $\sim 14 \%$ more muscle fibres (Hall \& Johnston 2003). This suggests that the reaction norm of larval fibre number with respect to the embryonic temperature regime differs in different populations, as was previously shown for the Atlantic herring (Johnston et al. 1998) and the Atlantic salmon (Johnston et al. 2000b).

\section{Adult fish}

The third and final stage of myogenesis in fast muscle is mosaic hyperplasia, involving the activation of myogenic progenitors residing throughout the myotome (Rowlerson \& Veggetti 2001). The recruitment of fast muscle fibres continues in adult stages until 40\% of the maximum body length is reached (Weatherley et al. 1988). A total of 65 adult cod that had stopped recruiting fast muscle fibres were sampled and this subset of fish had an average body length and mass of $41.1 \pm 0.5 \mathrm{~cm}$ and $1023 \pm 48 \mathrm{~g}$, respectively. Fig. 3 illustrates the banding patterns obtained for individuals homozygous for the absence $\left(\operatorname{PanI}^{\mathrm{AA}}\right)$ and presence $\left(P_{a n I^{\mathrm{BB}}}\right)$ of the polymorphic DraI site as well as the heterozygote $\left(\operatorname{Pan} \mathrm{I}^{\mathrm{AB}}\right)$. An ANOVA model with population, PanI genotype and development temperature as variables, explained $41 \%$ of the variation in fibre number, although the effect of population was not significant. However, the effect of the PanI genotype was strongly confounded by that of population in the full data set because all the coastal population had the PanI ${ }^{\mathrm{AA}}$ genotype. A model with only development temperature and PanI genotype as variables, explained $39 \%$ of the variation, with the effects of both factors being significant (development temperature: $F_{2,60}=$ 4.29; $\mathrm{p}=0.018$; PanI genotype: $\left.F_{2,60}=10.7, \mathrm{p}<0.0001\right)$. Analysis of the 49 samples from the NEA population alone enabled inferences to be made about the signifi- 


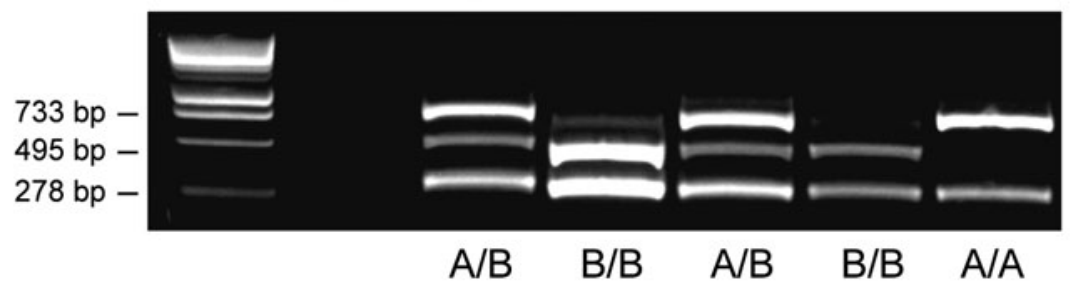

Fig. 3. Agarose gel showing the 3 pantophysin (PanI) genotypes after DraI digesting the third intron

cance of developmental temperature and PanI genotype without the confounding effect of population. This analysis indicated a significant effect of the PanI genotype on fibre number for the NEA population $(\mathrm{p}=0.002)$. A post-hoc Tukey's test revealed than the $\operatorname{PanI}^{\mathrm{BB}}$ genotype was associated with a significantly higher FFN than the PanI ${ }^{\mathrm{AB}}$ genotype $(\mathrm{p}=0.001)$ (Table 1). There was no significant difference between the 2 homozygous genotypes, perhaps due to the very low number of PanI $^{\mathrm{AA}}$ alleles present in the sample. Pantophysin is an integral membrane protein found in small cytoplasmic vesicles which may play a role, albeit yet uncharacterised, in intracellular trafficking pathways (Haass et al. 1996, Brooks et al. 2000). The genes controlling muscle fibre number have also not been characterised, hence the mechanism linking FFN and PanI genotype is entirely unknown, although a general correlation with growth has been established (Jónsdóttir et al. 2008).

The average FFN for the NEA population alone was $11 \%$ higher at the $4^{\circ} \mathrm{C}(92000 \pm 4000 \mathrm{SE}, \mathrm{n}=13)$ than at the $8^{\circ} \mathrm{C}(83000 \pm 3000, \mathrm{n}=20)$ embryonic treatment, although the effect of temperature did not reach significance for this subset of the data $\left(F_{244}=2.62 ; \mathrm{p}=0.084\right)$, probably due to the small sample size. Persistent effects of embryonic temperature on FFN have previously been reported for Atlantic salmon (Johnston et al. 2003, Macqueen et al. 2008). A potential mechanism whereby embryonic temperature could affect adult muscle growth has been identified (Macqueen et al. 2008). In zebrafish, dye tracing experiments have shown that the somites rotate $90^{\circ}$ starting at the midpoint of segmentation and the anterior cells migrate

Table 1. Gadus morhua. Final number of fast muscle fibres (mean $\pm \mathrm{SE}$; no. of fish in parentheses) in the myotomes of northeast Arctic (NEA) and Norwegian coastal (NC) populations of Atlantic cod in relation to pantophysin (PanI) genotypes and temperature to first feeding. $\mathrm{NR}=$ not represented

\begin{tabular}{|ccccc|}
\hline & Temp $\left({ }^{\circ} \mathrm{C}\right)$ & $\operatorname{PanI}^{\mathrm{AA}}$ & $\operatorname{PanI}^{\mathrm{AB}}$ & $\operatorname{PanI}^{\mathrm{BB}}$ \\
\hline $\mathrm{NEA}$ & 4 & $87000(2)$ & $82000 \pm 4500(6)$ & $105000 \pm 4500(5)$ \\
& 6 & $\mathrm{NR}$ & $81000 \pm 2500(10)$ & $83000 \pm 5000(7)$ \\
$\mathrm{NC}$ & 8 & $82000(2)$ & $77500 \pm 2500(11)$ & $92000 \pm 5000(7)$ \\
& 6 & $71000 \pm 2500(16)$ & $\mathrm{NR}$ & $\mathrm{NR}$ \\
\hline
\end{tabular}

laterally to form a layer external to the myotomal muscle fibres (the external cell layer) (Hollway et al. 2007). The external cell layer in teleosts is analogous to, and has many of the functional features of, the amniote dermomyotome (Gros et al. 2005, Relaix et al. 2005) that give rise to the skin, various pectoral fin muscles and Pax7 expressing myogenic precursors in the myotomal muscle (Hollway et al. 2007). Self-renewing undifferentiated Pax7 expressing cells persist in the external cell layer after hatching, and provide myogenic precursors that are utilised during larval muscle growth and remain resident in the myotome at later stages (Hollway et al. 2007, Stellabotte et al. 2007). Morpholino knock-down experiments of the master transcription factors involved in myogenic lineage specification, myoD and myf5, resulted in an increase in the number of Pax3/7 expressing cells in the external cell layer of larval zebrafish (Hammond et al. 2007). In Atlantic salmon, heterochronies in the expression of myf5 with respect to developmental stage have been reported in embryos reared at different temperatures (Macqueen et al. 2007). Heterochronies in the expression of myoD family members with development temperature provide a plausible mechanism for the modulation of Pax7 expressing cells in the external cell layer, hence also of the pool of myogenic stem cells available for postembryonic muscle growth. The hypothesis that temperature modulates the number of $\operatorname{Pax} 7$ expressing cells in the embryonic external cell layer and the present results showing differences in FFN in adult cod should be further tested in future experiments.

In summary, we found a significant difference in final fibre number between Norwegian coastal and northeast Arctic cod populations, as well as a significant effect of development temperature when the entire data set was analysed. All the NC cod studied had the PanI ${ }^{\mathrm{AA}}$ genotype compared with only $8 \%$ of the NEA population having the same genotype, heavily confounding the results. However, considering the NEA cod alone, the final fibre number was significantly higher in the $P_{a n I}{ }^{\mathrm{BB}}$ than in the $\operatorname{PanI}^{\mathrm{AB}}$ genotype. 
Acknowledgements. We thank M. Abercromby for excellent technical assistance throughout the study, and C. Paxton of the School of Mathematics and Statistics, University of St. Andrews for statistical support. This study was financed by the Norwegian Research Council (Grant No. 159672/S40).

\section{LITERATURE CITED}

Brander K (ed) (1994) Spawning and life history information for North Atlantic cod stocks. ICES Cooperative Research Report 205. Copenhagen, Denmark

Brooks S, Johnston IA (1993) Influence of development and rearing temperature on the distribution, ultrastructure and myosin sub-unit composition of myotomal muscle fibre types in the plaice Pleuronectes platessa. Mar Biol 117: 501-513

Brooks CC, Scherer PE, Cleveland K, Whittemore JL, Lodish HF, Cheatham B (2000) Pantophysin is a phosphoprotein component of adipocyte transport vesicles and associates with GLUT4-containing vesicles. J Biol Chem 275: 2029-2036

> Case RAJ, Hutchinson WF, Hauser L, Van Oosterhout C, Carvalho GR (2005) Macro- and micro-geographic variation in pantophysin (PanI) allele frequencies in NE Atlantic cod Gadus morhua. Mar Ecol Prog Ser 301:267-278

Case RAJ, Hutchinson WF, Hauser L, Buehler V and others (2006) Association between growth and PanI* genotype within Atlantic cod full-sibling families. Trans Am Fish Soc 135:241-250

Fevolden SE, Pogson GH (1997) Genetic divergence at the synaptophysin (SypI) locus among Norwegian coastal and northeast Arctic populations of Atlantic cod. J Fish Biol 51: 895-908

Galloway T, Kjorsvik E, Kryvi H (1998) Effect of temperature on viability and axial muscle development in embryos and yolk-sac larvae of the northeast Arctic cod Gadus morhua. Mar Biol 132:559-567

> Galloway TF, Kjorsvik E, Kryvi H (1999) Muscle growth and development in Atlantic cod larvae Gadus morhua L. related to different somatic growth rates. J Exp Biol 202: $2111-2120$

Gjerde B, Terjesen BF, Barr Y, Lein I, Thorland I (2004) Genetic variation for juvenile growth and survival in Atlantic cod Gadus morhua. Aquaculture 236:167-177

Greer-Walker M, Bird AC, Pull GA (1972) The total number of white skeletal muscle fibres in cross-section as a character for stock separation in North Sea herring Clupea harengus. J Cons Int Explor Mer 34:238-243

Gros J, Manceau M, Thome V, Marcelle C (2005) A common somitic origin for embryonic muscle progenitors and satellite cells. Nature 435:954-958

Hall TE, Johnston IA (2003) Temperature and developmental plasticity during embryogenesis in the Atlantic cod Gadus morhua. Mar Biol 142:833-840

Hammond CL, Hinits Y, Osborn DP, Minchin JE, Tettamanti G, Hughes SM (2007) Signals and myogenic regulatory factors restrict pax 3 and $\operatorname{pax} 7$ expression to dermomyotome-like tissue in zebrafish. Dev Biol 302:504-521

Haass NK, Kartenbeck J, Leube RE (1996) Pantophysin is a ubiquitously expressed synaptophysin homologue and defines constitutive transport vesicles. J Cell Biol 134:731-746

Hempel G, Blaxter JHS (1961) The experimental modification of meristic characters in herring Clupea harengus L. J Cons Int Explor Mer 26:336-346

> Hollway GE, Bryson-Richardson RJ, Berger S, Cole NJ, Hall TE, Currie PD (2007) Whole-somite rotation generates muscle progenitor cell compartments in the developing zebrafish embryo. Dev Cell 12:207-219

Imsland AK, Jónsdóttir ÓDB (2003) Linking population genetics and growth properties of Atlantic cod. Rev Fish Biol Fish 13:1-26

Johnston IA (2006) Environment and plasticity of myogenesis in teleost fish. J Exp Biol 209:2249-2264

Johnston IA, Cole NJ, Abercromby M, Vieira VLA (1998) Embryonic temperature modulates muscle growth characteristics in larval and juvenile herring. J Exp Biol 201: 623-646

Johnston IA, Strugnell G, McCraken M, Johnstone R (1999) Muscle growth and development in normal-sex-ratio and all-female diploid and triploid Atlantic salmon. J Exp Biol 202:1991-2016

> Johnston IA, Alderson D, Sandham C, Dingwall A and others (2000a) Muscle fibre density in relation to the colour and texture of smoked Atlantic salmon Salmo salar L. Aquaculture 189:335-349

> Johnston IA, McLay HA, Abercromby M, Robins D (2000b) Phenotypic plasticity of early myogenesis and satellite cell numbers in Atlantic salmon spawning in upland and lowland tributaries of a river system. J Exp Biol 203: $2539-2552$

Johnston IA, Manthri S, Alderson R, Smart A and others (2003) Freshwater environment affects growth rate and muscle fibre recruitment in seawater stages of Atlantic salmon Salmo salar. J Exp Biol 206:1337-1351

Johnston IA, Abercromby M, Vieira VLA, Sigursteindóttir RJ, Kristjánsson BK, Sibthorpe D, Skúlason S (2004) Rapid evolution of muscle fibre number in post-glacial populations of Arctic charr Salvelinus alpinus. J Exp Biol 207: $4343-4360$

> Jónsdóttir ODB, Imsland AK, Danílsdóttir AK, Marteinsdóttir G (2002) Genetic heterogeneity and growth properties of two different genotypes of Atlantic cod Gadus morhua L. at two spawning sites off south Iceland. Fish Res 55: $37-47$

Jónsdóttir IG, Marteinsdóttir G, Pampoulie C (2008) Relation of growth and condition with the PanI locus in Atlantic cod Gadus morhua L. around Iceland. Mar Biol 154: $867-874$

Karlsson S, Mork J (2003) Selection-induced variation at the Pantophysin locus (PanI) in a Norwegian fjord population of cod Gadus morhua L. Mol Ecol 12:3265-3274

Løken S, Pedersen T, Berg E (1994) Vertebrae numbers as an indicator for recruitment mechanisms of coastal cod of northern Norway. ICES Mar Sci Symp 198:510-519

> López-Albors O, Ayala MD, García-Alcázar A, Abellán E, Latorre R, Ramírez-Zarzosa G, Vázquez JM (2003) Early temperature effects on muscle growth dynamics and histochemical profile of muscle fibres of sea bass Dicentrarchus labrax L. during larval and juvenile stages. Aquaculture 220:385-406

- Macqueen DJ, Robb D, Johnston IA (2007) Temperature influences the coordinated expression of myogenic regulatory factors during embryonic myogenesis in Atlantic salmon (Salmo salar L.). J Exp Biol 210:2781-2794

> Macqueen DJ, Robb D, Olson T, Meltsveit L, Johnston IA (2008) Temperature during the first half of embryogenesis programs the growth trajectory and muscle phenotype in adult Atlantic salmon. Biol Lett. doi:10.1098/rsbl.2007. 0620

- Martell DJ, Kieffer JD (2007) Persistent effects of incubation temperature on muscle development in larval haddock Melanogrammus aeglefinus L. J Exp Biol 210:1170-1182 Nordeide JT (1998) Coastal and northeast Arctic cod-Do 
they mingle at the spawning grounds in Lofoten? Sarsia 83:373-379

Nordeide JT, Folstad I (2000) Is cod a lekking or a promiscuous group spawner? Fish Fish 1:90-93

Pinheiro JC, Bates DM (2000) Mixed-effect models in S and Splus. Springer, Berlin

Pogson GH (2001) Nucleotide polymorphism and natural selection at the pantophysin (PanI) locus in the Atlantic cod Gadus morhua L. Genetics 157:317-330

Pogson GH, Fevolden SE (2003) Natural selection and the genetic differentiation of coastal and Arctic populations of the Atlantic cod in northern Norway: a test involving nucleotide sequence variation at the pantophysin (PanI) locus. Mol Ecol 12:63-74

Pogson GH, Mesa KA, Boutilier RG (1995) Genetic population structure and gene flow in the Atlantic cod Gadus morhua: a comparison of allozyme and nuclear RFLP loci. Genetics 139:375-385

Editorial responsibility: Roderick Finn, Bergen, Norway
Relaix F, Rocancourt D, Mansouri A, Buckingham M (2005) A Pax3/Pax7-dependent population of skeletal muscle progenitor cells. Nature 435:948-953

Rowlerson A, Veggetti A (2001) Cellular mechanisms of postembryonic muscle growth in aquaculture species. In: Johnston IA (ed) Muscle development and growth. Fish Physiol 18:103-140

Stellabotte F, Dobbs-McAuliffe B, Fernandez DA, Feng X, Devoto SH (2007) Dynamic somite cell arrangements lead to distinct waves of myotome growth. Development 134: $1253-1257$

Walters C, Maguire JJ (1996) Lessons for stock assessment from the northern cod collapse. Rev Fish Biol Fish 6: 125-137

Weatherley AH, Gill HS, Lobo AF (1988) Recruitment and maximum diameter of axial muscle fibres in teleosts and their relationship to somatic growth and ultimate size. J Fish Biol 33:851-859

Submitted: March 28, 2008; Accepted: October 1, 2008 Proofs received from author(s): November 20, 2008 